\title{
Different methods of evaluation of Monilinia laxa on apricot flowers and branches
}

\section{J. Del Cueto' ${ }^{1}$, P. Stefani ${ }^{2}$, T. Oberhänsli' ${ }^{2}$, G. Roch ${ }^{3}$, L. Brun ${ }^{4}$, J.-M. Audergon ${ }^{5}$, D. Christen ${ }^{1}$}

${ }^{1}$ Agroscope Changins-Wädenswil Research Station ACW, Schloss, P.O. Box 185, 8820 Wädenswil, Switzerland.

${ }^{2}$ Department of Crop Sciences, FiBL, Ackerstrasse $113 \mathrm{CH}-5070$ Frick, Switzerland.

${ }^{3}$ CEP Innovation, 23 rue Jean Baldassini, F-69364 Lyon, France.

${ }^{4}$ INRA, UERI, Domaine de Gotheron, 26320 Saint-Marcel-lès-Valence, France.

5UR1052 GAFL Unité de Génétique et d'Amélioration des Fruits et Légumes, INRA, 84143 Montfavet, France.

\section{State of the art}

$\checkmark$ Organic apricot production is currently not profitable.

$\checkmark$ The main obstacle to sustainable profitability is brown rot caused by the fungus Monilinia laxa (Aderh. \& Ruhl)

$\checkmark$ In the current apricot germplasm no source of total resistance has been shown, but some varieties are expressing interesting levels of tolerance.

$\checkmark$ A good evaluation of the M. laxa symptoms is essential for a precise diagnosis of the infection and to appreciate differences between tolerant and susceptible varieties and genotypes.
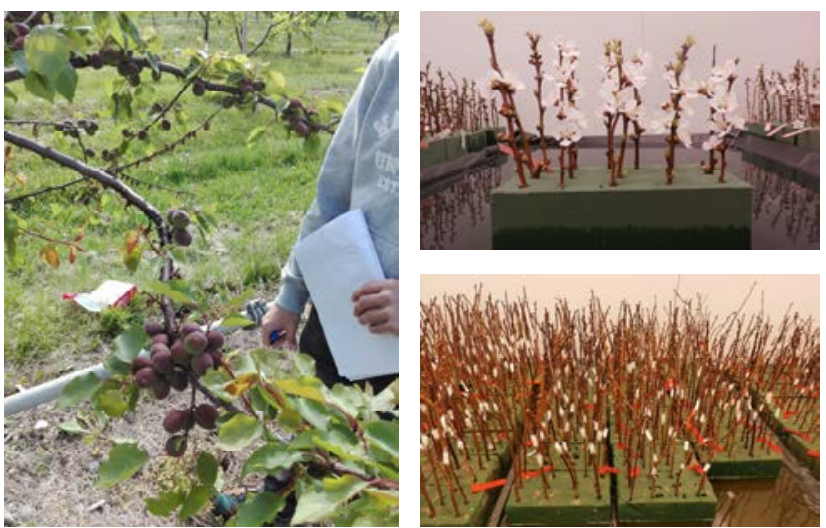

\section{Results and Conclusions}

$\checkmark$ Different levels of infection were observed within the bi-parental population for the three controlled phenotyping evaluations.

$\checkmark$ Symptoms in petals were not linked with the Monilinia infection according to our observations. The infection with the spores on the pistil test was very low.

$\checkmark$ Good segregation was observed for the visual assessment and for the evaluation test on branches

$\checkmark$ There was not a good correlation between the visual assessment in the field compare with the evaluation of branches and flowers.

$\checkmark$ There was not a good correlation neither between the three evaluations under controlled conditions.

$\checkmark$ Based onto the observed variability, a QTL approach can be applied for assessing the genetic components involved in Monilinia resistance.
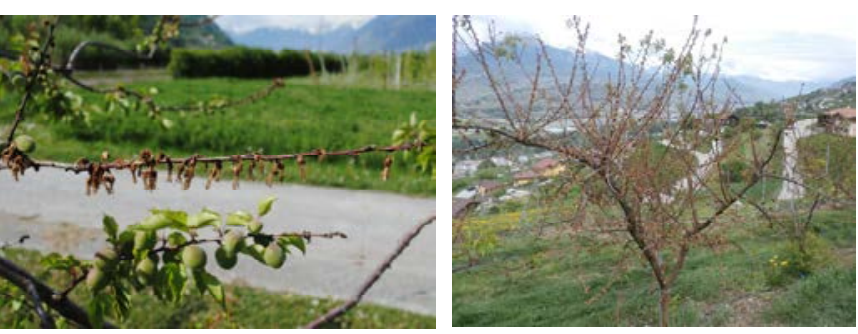

\section{Materials and methods}

$\checkmark$ Different evaluation methods were carried out on a bi-parental population between Bakour (tolerant to $M$. laxa) and Bergeron (susceptible):

1) Visual evaluation of Monilinia symptoms was carried on the trees (from 0 to $100 \%$ of infection) 35 days after full blossom. Wheater dependant method.

2) Evaluations Under controlled conditions on each genotype:

a) A spore suspension $\left(10^{4} / \mathrm{ml}\right)$ of $M$. laxa was sprayed on flowers $\left(20^{\circ} \mathrm{C}\right.$ $90 \%$ HR, 14 hours day), and \% of infected flowers (necrotic petals) was measured 36 hours after

b) A drop of spores $\left(10^{5} / \mathrm{ml}\right)$ was inoculated with a pipette directly on the pistil when the flower was in stage F. Flower / branches infection was evaluated.

c) A plug of $\mathrm{M}$. laxa mycelium was added on branches $\left(20^{\circ} \mathrm{C}, 80 \% \mathrm{HR}\right.$, darkness), and 8 days after the length of the reaction was measured.
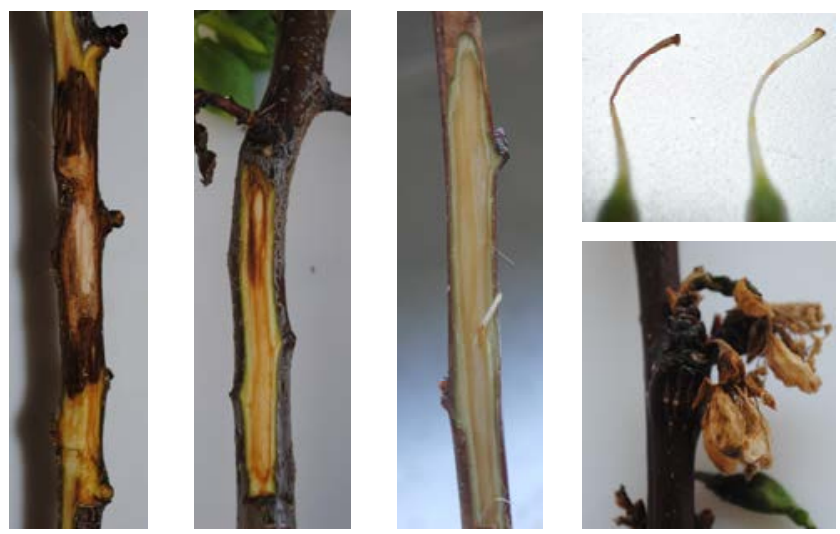

\begin{tabular}{|cccc|}
\hline & branches & flowers & visual \\
branches & 1 & 0.14 & 0.21 \\
flowers & & 1 & -0.08 \\
visual & & & 1 \\
\hline
\end{tabular}

80,00

60,00

40,00

20,00

0,00<smiles>C1=CC[CH+]1</smiles>

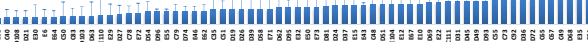

Length of infection (in $\mathrm{mm}$ ) in branches of a bi-parental population 8 days after inoculation with mycelium of $M$. laxa under controlled conditions. In red circle the two parental Bergeron (susceptible) and Bakour (tolerant). Grey box indicates the Correlation Coefficient $\left(R^{2}\right)$ between the three evaluations.

(⿸丆口

Biocontrolt ocontro

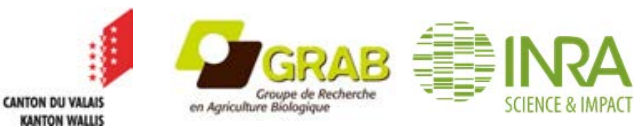

Office fédéral de l'agriculture OFAG 